\title{
THIẾU MÁU CHI CÂPP TÍNH DO TẮC ĐỘNG MẠCH: KẾT QUẢ ĐIỀU TR! NGOẠI KHOA VÀ MỘT SỐ YẾU TỐ LIÊN QUAN
}

\author{
Đoàn Quốc Hung*, Vũ Hải Trung**
}

\section{TÓM TẮT}

Hồi cứu mô tả cắt ngang trên 67 bệnh nhân với 76 chi bệnh thiếu máu cấp tính do tắc động mạch tại bệnh viện $\mathrm{HN}$ Việt Đức được điều trị phẫu thuật. Đa số tắc mạch chi dưới $(85,53 \%)$, chi trên $(14,47 \%)$. Kết quả sớm sau 7 ngày phẫu thuật: bảo tồn chi $75 \%$, cắt cụt thì đầu $15,79 \%$, cắt cụt thì hai $6,58 \%$. Không có trường hợp nào tắc mạch chi trên phải cắt cụt. Mức độ thiếu máu chi khi vào viện, thời gian thiếu máu, vị trí tắc động mạch là các yếu tố ảnh hưởng tới kết quả sớm sau phẫu thuật $(\mathrm{p}<0,05)$. Tỷ lệ cắt cụt chi do tắc mạch cấp còn cao. Mức độ thiếu máu, thời gian thiếu máu, vị trí tắc động mạch là các yếu tố tiên lượng chính.

Tù khóa: thiếu máu chi cấp tính, điều trị, yếu tố tiên lượng

SUMMARY: Cross-sectional descriptive retrospective study on 67 patients (76 extremities) with acute extremities ischemia have been treated by surgery at Viet Đuc hospital. The majority was occlusion of lower limb (85,53\%), upper limb $(14,47 \%)$. Early treatment results within 7 days post-operation: $75 \%$ limb salvage, first amputation $15,79 \%$, second amputation 6,58\%. No case of upper limb occlusion need to be amputated. There were correlation between the early results post-operation and clinical categories of acute limb ischemia, ischemic duration, location of occlusion $(p<0.05)$. The rate of amputation remains high. Clinical categories of acute limb ischemia: ischemic duration, location of occlusion are the key prognostic factors.

Keywords: acute ischemic limb, prognostic factors.

\section{I. ĐẶT VẤN Đî̀}

Bệnh thiếu máu chi cấp tính là một cấp cứu nội-ngoại khoa mạch máu, đòi hỏi phải nhập viện kịp thời, chẩn đoán nhanh và điều trị cấp cứu. Cuộc cách mạng trong điều trị bệnh thiếu máu cấp tính chi xảy ra sau sự ra đời của kỹ thuật lấy cục huyết khối bằng catheter có bóng Fogarty vào năm 1963[1]]. Cùng với các tiến bộ của y học nói chung và phẫu thuật mạch máu nói riêng, việc điều trị phẫu thuật các trường hợp tắc động mạch chi cấp tính đã trở nên đơn giản hơn rất nhiều, là nhân tố quyết định không chỉ đến sự sống còn của chi mà còn cả sự sống còn của bệnh nhân. Tuy nhiên tỷ lệ tử vong cũng như cắt cụt sau phẫu thuật vẫn còn cao $(10-25 \%)$ theo một số thống kê. Qua thực tế lâm sàng trong những năm gần đây tại các bệnh viện nói chung và bệnh viện Hữu Nghị Việt Đức nói riêng chúng tôi nhận thấy, trong khi các cấp cứu chấn thương - vết thương mạch máu ngoại vi chiếm tỷ lệ khoảng $2 \%$ cấp cứu ngoại chung và có kết quả điều trị tốt[2] thì số lượng bệnh nhân bệnh thiếu máu chi cấp tính do tắc động mạch ngày càng nhiều, nguyên nhân đa dạng[]ㅡ, kết quả điều trị chưa được như mong muốn. Bên cạnh một số đề tài nghiên cứu khu trú về chi trên hoặc chi dưới, để có được đánh giá tổng thể tình hình thiếu máu chi cấp tính do bệnh lý nói chung tại bệnh viện Hữu Nghị Việt Đức, tìm hiểu một số yếu tố tiên lượng bệnh, chúng tôi thực hiện nghiên cứu với hai mục tiêu: Đánh giá

\footnotetext{
* Bệnh viện HN Việt Đúc

** Bệnh viện Thanh Nhàn Hà Nội

Ngườ chịu trách nhiệm khoa học: PGS.TS. Đoàn Quốc Hung Ngày nhận bài: 10/02/2017- Ngày Cho Phép Đăng: 10/03/2017 Phản Biện Khoa họ: PGS.TS. Đặng Ngọc Hùng GS.TS. Lê Ngọc Thành
} 
kết quả điều trị bệnh thiếu máu chi cấp tính do tắc động mạch tại bệnh viện Việt Đức và nhận xét một số yếu tố ảnh hưởng đến kết quả điều trị bệnh lý này.

\section{II. ĐỐI TƯợNG VÀ PHƯƠNG PHÁP NGHIÊN CỨU}

Gồm tất cả các bệnh nhân được chẩn đoán bệnh thiếu máu chi (chi trên, chi dưới) cấp tính do tắc động mạch được điều trị bằng phẫu thuật tại Bệnh viện Hữu Nghị Việt Đức từ 1/2014 đến 12/2015. Không giới hạn tuổi, giới, nghề nghiệp. Hồ sơ bệnh án đầy đủ các chỉ số cần cho nghiên cứu. Nghiên cứu hồi cứu mô tả cắt ngang. Sử dụng cỡ mẫu thuận tiện. Tất cả bệnh nhân được nghiên cứu theo một mẫu hồ sơ thống nhất. Các số liệu nghiên cứu được mã hóa phân tích và xử lý trên máy tính bằng phần mềm SPSS 18.0.

\section{KẾT QUẢ NGHIÊN CÚU}

Từ $1 / 2014$ đến $12 / 2015$, tại bệnh viện Hữu Nghị Việt Đức có 67 bệnh nhân ( $\mathrm{N}=67)$ với 76 chi $(\mathrm{n}=76)$ thiếu máu cấp tính chi do tắc động mạch đủ tiêu chuẩn nghiên cứu với các đặc điểm như sau

\subsection{Kết quả điều trị sớm sau phẫu thuật \\ 3.1.1. Phương pháp phẫu thuật}

64 chi trên tổng số 76 chi $(84,21 \%)$ đã được tái lưu thông tuần hoàn, trong đó các trường hợp lấy máu cục kèm theo mở cân chiếm tỷ lệ cao nhất $(42,11 \%)$, chỉ có 3 BN lấy máu cục kết hợp với bắc cầu. Cắt cụt thì đầu 12 trường hợp $(15,79 \%)$.

\subsubsection{Kết quả sớm sau phẫu thuật}

Bảng 3.1. Kết quả sớm sau mổ $(\mathrm{n}=76)$

\begin{tabular}{|c|c|c|}
\hline Kết quả sớm & Số chi & Tỷ lệ \% \\
\hline Bảo tồn chi & $\mathbf{5 7}$ & $\mathbf{7 5}$ \\
\hline Cắt cụt thì $\mathbf{1}$ & $\mathbf{1 2}$ & $\mathbf{1 5 , 7 9}$ \\
\hline Cắt cụt thì $\mathbf{2}$ & $\mathbf{5}$ & $\mathbf{6 , 5 8}$ \\
\hline Tử vong & $\mathbf{0}$ & $\mathbf{0}$ \\
\hline Xin về & $\mathbf{2}$ & $\mathbf{2 , 6 3}$ \\
\hline
\end{tabular}

Bảng 3.2. Kết quả sớm sau mổ theo vị trí tắc mạch chi trên hay chi dưới $(\mathrm{n}=76)$

\begin{tabular}{|c|c|c|c|c|c|}
\hline Kị trít quả & Bảo tồn chi & Cắt cụt thì $\mathbf{1}$ & Cắt cụt thì $\mathbf{2}$ & Tử vong & Xin về \\
\hline Chi trên & $11(14,47 \%)$ & $0(0 \%)$ & $0(0 \%)$ & $0(0 \%)$ & $0(0 \%)$ \\
\hline Chi dưới & $46(60,53 \%)$ & $12(15,79 \%)$ & $5(6,58 \%)$ & $0(0 \%)$ & $2(0 \%)$ \\
\hline
\end{tabular}

Bảng 3.3: Liên quan giữa kết quả sớm sau phẫu thuật với vị trí tắc động mạch chi trên và chi dưới trên siêu âm Doppler (đã loại trừ 2 trường hợp xin về) $(\mathrm{n}=74)$

\begin{tabular}{|c|c|c|l|}
\hline Vị trí Kết quả & Bảo tồn chi & \multicolumn{1}{|l|}{ Cắt cụt } & p \\
\hline Chi trên & $11(14,9 \%)$ & $0(0 \%)$ & $\begin{array}{l}\mathrm{p}=0,044 \\
\mathrm{p}<0,05)\end{array}$ \\
\hline Chi dưới & $46(62,1 \%)$ & $17(23,0 \%)$ & $\mathrm{r}$ \\
\hline
\end{tabular}


Trong nghiên cứu này, khi tắc mạch chi trên thì tỉ lệ bảo tồn chi tới $100 \%$. Kết quả $\mathrm{p}=0,044$ cho thấy có sự khác biệt có ý nghĩa thống kê về kết quả sớm phẫu thuật giữa nhóm chi trên và chi dưới.

\subsubsection{Giai đọ̣n lâm sàng thiếu máu chi cấp tính}

Bảng 3.4: Giai đoạn lâm sàng thiếu máu chi cấp tính $(n=76)$

\begin{tabular}{|l|c|c|}
\hline \multicolumn{1}{|c|}{ Giai đoạn lâm sàng thiếu máu chi cấp tính } & Số chi $(\mathbf{n}=\mathbf{7 6})$ & Tỷ lệ \% \\
\hline IIa: Chi bị đe dọa (ranh giới) & 15 & $19,74 \%$ \\
\hline IIb: Chi bị đe dọa (ngay lập tức) & 49 & $64,47 \%$ \\
\hline III: Không hồi phục & 12 & $15,79 \%$ \\
\hline
\end{tabular}

Bảng 3.5: Liên quan giữa kết quả sớm sau phẫu thuật với mức độ thiếu máu chi trên lâm sàng (đã loại 2 trường hợp nặng xin về không đánh giá) $(n=74)$

\begin{tabular}{|c|c|c|c|}
\hline Giai đoạn & Kết quảo tồn chi & $\begin{array}{c}\text { Cắt cụt } \\
\text { thì } \mathbf{1}+\text { thì } \mathbf{2}\end{array}$ & \multirow{2}{*}{ p } \\
\cline { 1 - 3 } IIa & $15(20,27 \%)$ & $0(0 \%)$ & \multirow{2}{*}{$\mathrm{p}=0,00(<0.05)$} \\
\cline { 1 - 3 } IIb & $42(56,76 \%)$ & $5(6,76 \%)$ & \\
\cline { 1 - 3 } III & $0(0 \%)$ & $12(16,21 \%)$ & \\
\hline
\end{tabular}

Tất cả các trường hợp thiếu máu giai đoạn III phải cắt cụt, trong khi đó nếu chi thiếu máu giai đoạn IIa thì tỷ lệ giữ được chi là $100 \%$. Trong nhóm chi thiếu máu giai đoạn IIb, tỷ lệ bảo tồn được chi cũng rất cao (42 chi bảo tồn trong tổng số 47 chi thiếu máu giai đoạn IIb). Có liên quan một cách chặt chẽ giữa kết quả sớm sau mổ với mức độ thiếu máu chi trên lâm sàng $(\mathrm{p}<0,05)$

\subsubsection{Thòi gian tù khi xuất hiện triệu chúng} đầu tiên tới khi đự̛c phẫu thuật

Trong tổng số 76 chi chẩn đoán thiếu máu cấp tính do tắc động mạch, số chi có thời gian xuất hiện triệu chứng đến khi phẫu thuật trên 24 giờ chiếm tỷ lệ cao nhất $(60,53 \%)$, chỉ có 1 chi có thời gian thiếu máu dưới 6 giờ (chiếm 1,31\%). Thời gian thiếu máu trung bình là 2,29 2,06 ngày, ngắn nhất là 6 giờ, dài nhất là 208 giờ $(6,67$ ngày).

Bảng 3.6: Liên quan giữa kết quả sớm sau phẫu thuật với thời gian thiếu máu ( $\mathrm{n}=74)$

\begin{tabular}{|c|c|c|c|}
\hline Thời gian thiếu máu & Bảo tồn chi & Cắt cụt thì $\mathbf{1}$ và thì $\mathbf{2}$ & p \\
\hline$<24$ giờ $(\mathrm{n}=28)$ & $25(33,8 \%)$ & $3(4,1 \%)$ & \multirow{2}{*}{$\mathrm{p}=0,044$} \\
\hline$\geq 24$ giờ $(\mathrm{n}=46)$ & $32(43,2 \%)$ & $14(18,9 \%)$ & \\
\hline
\end{tabular}

Tỷ lệ bảo tồn chi ở nhóm bệnh nhân đến sớm trước 24 giờ cao hơn hẳn so với nhóm bệnh nhân đến muộn sau 24 giờ. Sự khác biệt này có ý nghĩa thống kê với $\mathrm{p}=0,044$. Nếu thời gian thiếu máu trước 6 giờ thì không có trường hợp nào phải cắt cụt thì đầu. Đa số các trường hợp cắt cụt thì đầu có thời gian thiếu máu trên 24 giờ (10 trong tổng số 12 trường hợp).

\section{BÀN LUẬA}

\subsection{Kết quả sớm điều trị phẫu thuật}

\subsubsection{Trường hợp bảo tồn chi}

Trong tổng số 76 chi được chẩn đoán thiếu máu cấp tính do tắc động mạch, 57 chi được bảo tồn chiếm tỷ lệ $75 \%$. Đây là các trường hợp thiếu máu giai đoạn sớm, thời gian thiếu máu ngắn. Kết 
quả này tương đồng với kết quả các nghiên cứu khác, nghiên cứu của Đặng Hanh Sơn tỷ lệ bảo tồn chi là $61,36 \%[3]$, nghiên cứu của tác giả Đỗ Kim Quế, với thời gian thiếu máu dưới 12 giờ thì tỷ lệ bảo tồn chi là $96,7 \%$; với thời gian thiếu máu trên 24 giờ thì tỷ lệ này giảm còn $51 \%[4]$. Nghiên cứu của Ilic $M$ và cộng sự, tỷ lệ bảo tồn chi là 77,7\%[ㅌ].

\subsubsection{Truờng hợp không bảo tồn đực chi}

Trong tổng số 67 bệnh nhân với 76 chi nghiên cứu, có 17 trường hợp phải cắt bỏ một phần chi (chiếm tỷ lệ 22,35\%), trong đó 12 trường hợp $(15,79 \%)$ cắt theo dự kiến trước mổ, 5 trường hợp cắt cụt thì hai $(6,58 \%)$ do tình trạng thiếu máu không cải thiện sau mổ lấy máu cục. Theo Đặng Hanh Sơn, tỷ lệ cắt bỏ một phần chi là $34,1 \%$ trong đó $31,82 \%$ trường hợp cắt theo dự kiến trước mổ, chỉ 1 trường hợp cắt cụt chi thì hai do tình trạng thiếu máu chi không cải thiện sau mổ lấy máu cục[]ㅡ. Nghiên cứu của Đỗ Kim Quế, tỷ lệ cắt cụt chiếm $11,6 \%$ [4]. Theo Currie IS và cộng sự năm 2007 tỷ lệ cắt cụt là 21,6\%[]], của tác giả ILic $\mathrm{M}$ là $10.3 \%$ [5] . Cắt bỏ phần chi hoại tử có tác dụng tránh biến chứng nhiễm trùng nhiễm độc khi các sản phẩm sinh ra do quá trình chuyển hóa yếm khí trong thời gian thiếu máu theo đường tĩnh mạch về tim và đi khắp cơ thể.

\subsubsection{Các trường hợp tử vong hoặc xin về}

Trong nghiên cứu của chúng tôi không có trường hợp nào tử vong trong thời gian nằm viện. Tuy nhiên có 2 trường hợp nặng xin về, chiếm tỷ lệ $2,63 \%$. Tỷ lệ tử vong và xin về của Đặng Hanh Sơn là 4,55\%[3] . Tỷ lệ tử vong trong nghiên cứu của Đỗ Kim Quế là 15,9\%[]]. Tỷ lệ tử vong trong nghiên cứu của Ilic M 12\% [ㅍ]. Cũng theo các tác giả trên thế giới, tỷ lệ tử vong có liên quan đến các bệnh nội khoa kèm theo: suy tim, nhồi máu cơ tim, loạn nhịp, tai biến mạch não, đái tháo đường, cao huyết áp, ung thư...Điều này lý giải vì sao có sự khác biệt về kết quả nghiên cứu giữa các tác giả.

\subsection{Một số yếu tố ảnh hưởng đến kết quả điều trị}

4.2.1. Thời gian tù̀ khi xuất hiện triệu chúng đến khi phẫu thuật

Có đến $60,53 \%$ các trường hợp đến muộn sau 24 giờ. Nghiên cứu của tác giả Đỗ Kim Quế tại bệnh viện Thống Nhất, số trường hợp đến muộn sau 24 giờ cũng chiếm tới 57,1\%[4].

Có sự liên quan giữa thời gian xuất hiện triệu chứng đến khi $\mathrm{BN}$ được phẫu thuật với kết quả điều trị với $\mathrm{p}=0,044(\mathrm{p}<0,05)$. Tỷ lệ $\mathrm{BN}$ phải cắt cụt nếu đến trước 24 giờ là $4,1 \%$, nếu sau 24 giờ là $18,9 \%$. Nghiên cứu của Bates GJ và cộng sự, $75 \%$ số $\mathrm{BN}$ thiếu máu dưới 12 giờ cho kết quả tốt, ngược lại tỷ lệ này chỉ là $37 \%$ khi thời gian thiếu máu trên 12 giờ [7]. Tác giả Đỗ Kim Quế nhận thấy nếu $\mathrm{BN}$ được mổ dưới 12 giờ tỷ lệ tử vong 3,5\%, tỷ lệ chi được bảo tồn là $96,6 \%$. Nếu $\mathrm{BN}$ được mổ sau 24 giờ tỷ lệ tương ứng là 19,6\% và $51 \%$ [4]. Nghiên cứu của tác giả Đặng Hanh Sơn năm 2001 cho kết quả nếu bệnh nhân đến trước 12 giờ không có trường hợp nào phải cắt cụt $(0 \%)$, nếu sau 12 giờ cắt cụt 43,6\% [3] ].

\subsubsection{Mức độ thiếu máu chi trên lâm sàng}

Nghiên cứu của chúng tôi cho thấy có sự liên quan giữa kết quả sớm sau phẫu thuật với mức độ thiếu máu chi trên lâm sàng $(p=0,00)$. Ở nhóm thiếu máu giai đoạn IIa (nhóm không có triệu chứng thần kinh hoặc giảm cảm giác rất nhẹ) không có bệnh nhân nào phải cắt cụt chi. Trong khi đó, tỷ lệ cắt cụt của nhóm bệnh nhân thiếu máu giai đoạn IIb (có rối loạn cảm giác nhiều, yếu cơ) trên tổng số chi là $6,76 \%$, tỷ lệ cắt cụt chi thiếu máu giai đoạn III (có dấu hiệu hoại tử, cứng khớp) trên tổng số chi là $16,21 \%$. Rutherford và cộng sự chỉ ra rằng khi chi thiếu máu giai đoạn III chỉ định cắt cụt chi là bắt buộc, việc tái lưu thông 
tuần hoàn là vô nghĩa[]]. Nghiên cứu của Currie IS (2007) chỉ ra có sự tương quan chặt chẽ giữa mất cảm giác $(\mathrm{p}=0.003)$ và mất vận động $(\mathrm{p}=$ 0.001 ) với tỷ lệ cắt cụt[6]. Nghiên cứu của Đặng Hanh Sơn chỉ ra nếu có rối loạn cảm giác, tỷ lệ cắt cụt lên tới $42.3 \%$. Nếu mất vận động tỷ lệ này là $68.5 \%$ [3]]. Khi một phần chi bị hoại tử phải cắt cụt để tránh huyết khối tĩnh mạch lan rộng, tắc mạch phổi, nhiễm trùng nhiễm độc toàn thân.

\subsubsection{Vị trí tắc}

Đa số các trường hợp tắc mạch ở chi dưới. Nghiên cứu của chúng tôi cho thấy có đến 65 trường hợp tắc mạch ở chi dưới chiếm 85,53\%. Tắc mạch chi trên cấp tính chỉ chiếm 14,47\% Nghiên cứu của Đỗ Kim Quế tại bệnh viện Thống Nhất, vị trí tắc ở chi dưới chiếm $83,64 \%$, vị trí tắc mạch ở chi trên chỉ chiếm 16,36\% [4].

Có sự liên quan giữa kết quả điều trị sớm sau phẫu thuật với vị trí tắc động mạch là ở chi trên hay chi dưới (với $\mathrm{p}=0,044$ ). Khi thiếu máu cấp tính xảy ra ở chi trên, không có trường hợp nào phải cắt cụt, trong khi đó có đến $23 \%$ trường hợp phải cắt cụt chi khi $\mathrm{BN}$ thiếu máu cấp tính ở chi dưới. Trong tổng số 17 chi cắt cụt, có 9 trường hợp do tắc động mạch đùi, 5 trường hợp tắc động mạch chậu, 2 trường hợp tắc động mạch khoeo, 1 trường hợp tắc chạc 3 chủ chậu. Tỷ lệ cắt cụt chi ở từng vị trí tắc cũng rất khác biệt, trong đó tắc động mạch đùi, động mạch chậu là cao nhất. Nếu bị tắc ở những vị trí này thì nguy cơ bị cắt cụt sẽ rất cao. So sánh với kết quả nghiên cứu của Đặng Hanh Sơn, trong 15 trường hợp cắt cụt, 2 trường hợp tắc tại động mạch chủ - chậu, 8 trường hợp tắc tại động mạch đùi chung, 2 trường hợp tắc tại động mạch đùi nông, 4 trường hợp tắc động mạch khoeo, 1 trường hợp tắc động mạch cánh tay. Tác giả cũng chỉ ra, động mạch chủ - chậu, động mạch đùi nông, động mạch cánh tay nếu bị tắc thì nguy cơ cắt cụt sẽ cao [3]].

\section{V.KẾT LUẬN}

Qua nghiên cứu 67 bệnh nhân với 76 chi thiếu máu cấp tính do tắc động mạch tại bệnh viện Hữu Nghị Việt Đức giai đoạn 2014 - 2015 chúng tôi nhận thấy: Đa số tắc mạch chi dưới $(85,53 \%)$, chi trên $(14,47 \%)$. Kết quả điều trị sớm sau 7 ngày phẫu thuật: bảo tồn chi $75 \%$, cắt cụt thì đầu $15,79 \%$, cắt cụt thì hai $6,58 \%$. Không có trường hợp nào tắc mạch chi trên phải cắt cụt. Mức độ thiếu máu chi trên lâm sàng, thời gian thiếu máu chi, vị trí tắc động mạch là các yếu tố ảnh hưởng tới khả năng bảo tồn chi của bệnh nhân.

\section{TÀI LIẸU THAM KHẢO}

1. T. J. Fogarty, J. J. Cranley, R. J. Krause et al (1963). A method for extraction of arterial emboli and thrombi. Surg Gynecol Obstet, 116, 241-244.

2. Nguyễn Hữu Ước, Chế Đình Nghĩa, Đoàn Quốc Hưng và cộng sự (2007). Đánh giá tình hình cấp cứu vết thương - chấn thương mạch máu ngoại vi tại Bệnh viện Việt Đức giai đoạn 2004 2006. Tạp chí y hoc Việt Nam, 4, 12-19.

3. Đặng Hanh Sơn (2001). Chẩn đoán và thái độ xủ trí nghẽn động mạch ngoại vi cấp tính, Trường Đại học Y Hà Nội.

4. Đỗ Kim Quế (2005). Các yếu tố tiên lượng tắc động mạch ngoại biên cấp tính. Tạp chí y hoc Việt Nam, Số chuyên đề tháng 1, 56-61.

5. M. Ilic, L. Davidovic, S. Lotina et al (2000). [Arterial embolisms of the lower extremities]. Srp Arh Celok Lek, 128 (7-8), 234-240.

6. I. S. Currie, S. J. Wakelin, A. J. Lee et al (2007). Plasma creatine kinase indicates major amputation or limb preservation in acute lower limb ischemia. J Vasc Surg, 45 (4), 733-739.

7. G. J. Bates và A. R. Askew (1984). Arterial embolectomy: a review of 100 cases. Aust N Z J Surg, 54 (2), 137-140.

8. R. B. Rutherford, J. D. Baker, C. Ernst et al (1997). Recommended standards for reports dealing with lower extremity ischemia: revised version. J Vasc Surg, 26 (3), 517-538. 